\title{
A Study on Identity of New Chinese Immigrants in Bangkok
}

\author{
Jianghua $\operatorname{Han}^{1}$ \\ ${ }^{1}$ College of Literature and Journalism of Sichuan University, Chengdu, China \\ Correspondence: Jianghua Han, College of Literature and Journalism, Sichuan University, No.24 South Section \\ 1, Yihuan Road, Chengdu City, Sichuan Province, China. E-mail: hanjianghua @ scu.edu.cn
}

\author{
Received: February 17, $2020 \quad$ Accepted: March 16, $2020 \quad$ Online Published: March 30, 2020 \\ doi:10.5539/ass.v16n4p87 \\ URL: https://doi.org/10.5539/ass.v16n4p87
}

This study is funded by "the Fundamental Research Funds for the central Universities", project NO: YJ201801; and is funded by Sichuan University, project NO: 2018hhs-38.

\begin{abstract}
Survey results of this study have showed that: The Chinese new immigrants in Bangkok have a consistency on ethnic identity; they all agree that they are Chinese. However, on the national identity and cultural identity, the identity of them has multi-tendency. There are $45.29 \%$ respondents identify China, $30.63 \%$ respondents identify Thailand, and $24.08 \%$ respondents identify both China and Thailand. The degree of identifying China of them has declined with the increase of their settlement years in Bangkok; however, their degree of identifying Thailand has increased with the increase of settlement years in Bangkok. The cultural identity is very complicated, they are increasingly accepting and identifying Thai culture with the increase of their settlement years in Bangkok; however, they did not deny or abandon Chinese culture, lots of people still identify Chinese culture. Especially in the identity of traditional culture, in general, the degree of identifying Chinese traditional culture of them has declined with the increase of their settlement years in Bangkok; however, the proportion of people who identify Chinese traditional culture is still much higher than people who identify Thai traditional culture.
\end{abstract}

Keywords: identity, New Chinese Immigrants, Bangkok

\section{Introduction}

With the establishment of the China-ASEAN Free Trade Area and the implementation of the national "Belt and Road" strategy, a large number of Chinese people have traveled to Thailand to work and study, thus forming a new Chinese group in Bangkok, Thailand, namely "new Chinese immigrants". They are active in all aspects of Thai society and play a very important role in Thai society. Knowing about the identity of new Chinese immigrants in Bangkok, on one hand, it will help Thai government formulate a national policy that is in line with national conditions, promoting the harmonious development of society. On the other hand, it will help Chinese government to formulate a better overseas Chinese policy, enhancing Chinese-Thai friendship.

This paper mainly studies the identity of new Chinese immigrants in Bangkok through questionnaire survey. The study mainly surveys from the following three aspects: ethnic identity, national identity, and cultural identity; intended to let people have a comprehensive understanding of the identity of new Chinese immigrants in Bangkok.

\section{Methodology}

This paper will use the method of questionnaire and statistical analysis to conduct the research, and it will be divided into the following steps:

First, determining the scope of new Chinese immigrants in Bangkok. We will use the following definition:

The "new Chinese immigrants" in this study refers to people who meet the following three conditions: First, they are born in China; second, they are native speakers of Chinese or ethnic languages in China; third, they are currently living in Bangkok more than half a year.

Second, dividing new Chinese immigrants in Bangkok into different categories according to the industry they are engaged in (including education and research, business and trade, diplomacy, medical, tourism, manufacturing, 
news and media, freelance). Then surveying 50 people by random sampling from each category (with a total of 400 people).

Third, conduct a statistical analysis of the questionnaire and write the survey results.

\section{Data Sources}

The data of this study all come from questionnaires and interviews in 2019. The detailed information of the respondents is as follows:
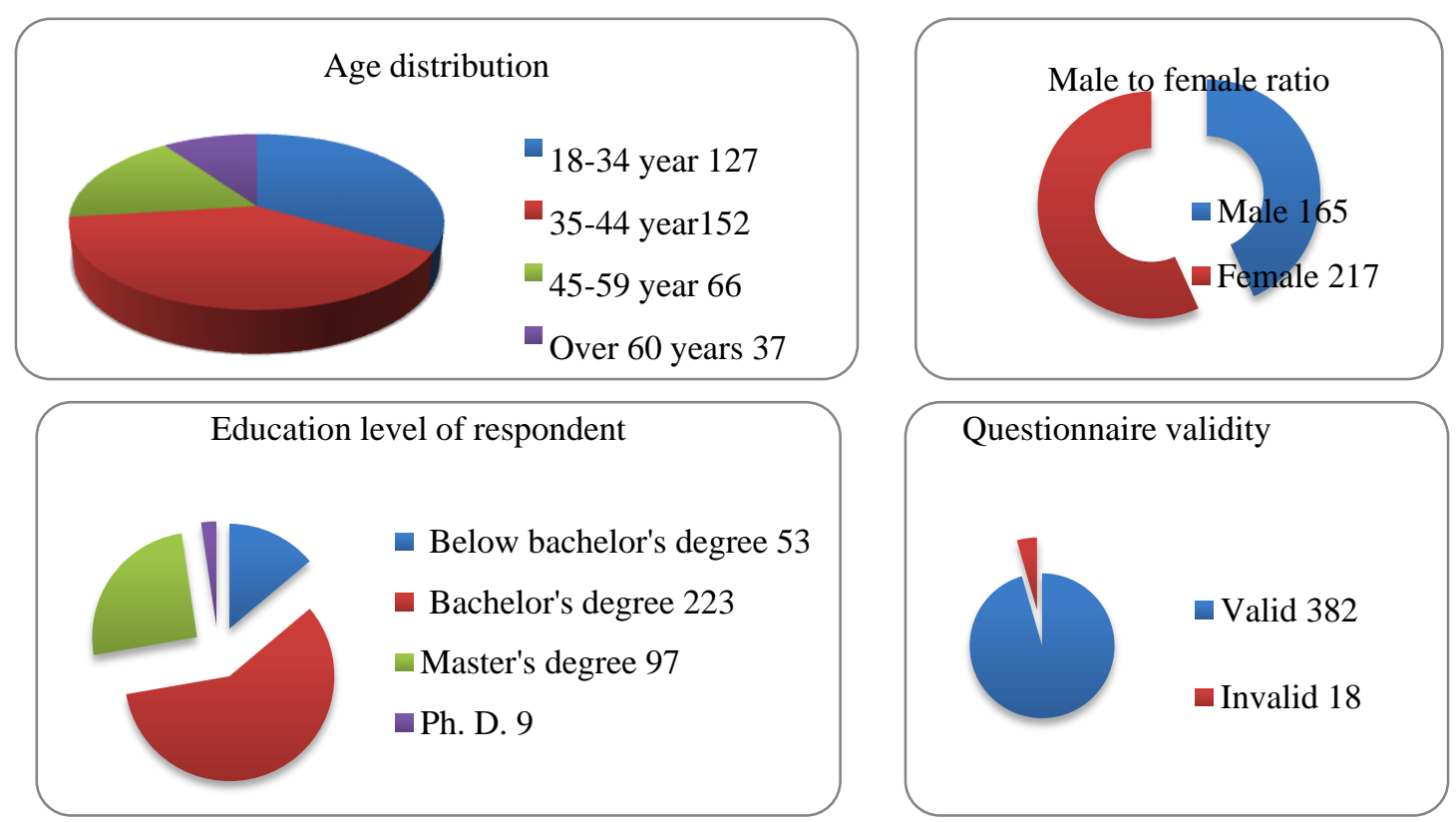

Figure 1. Information of respondent

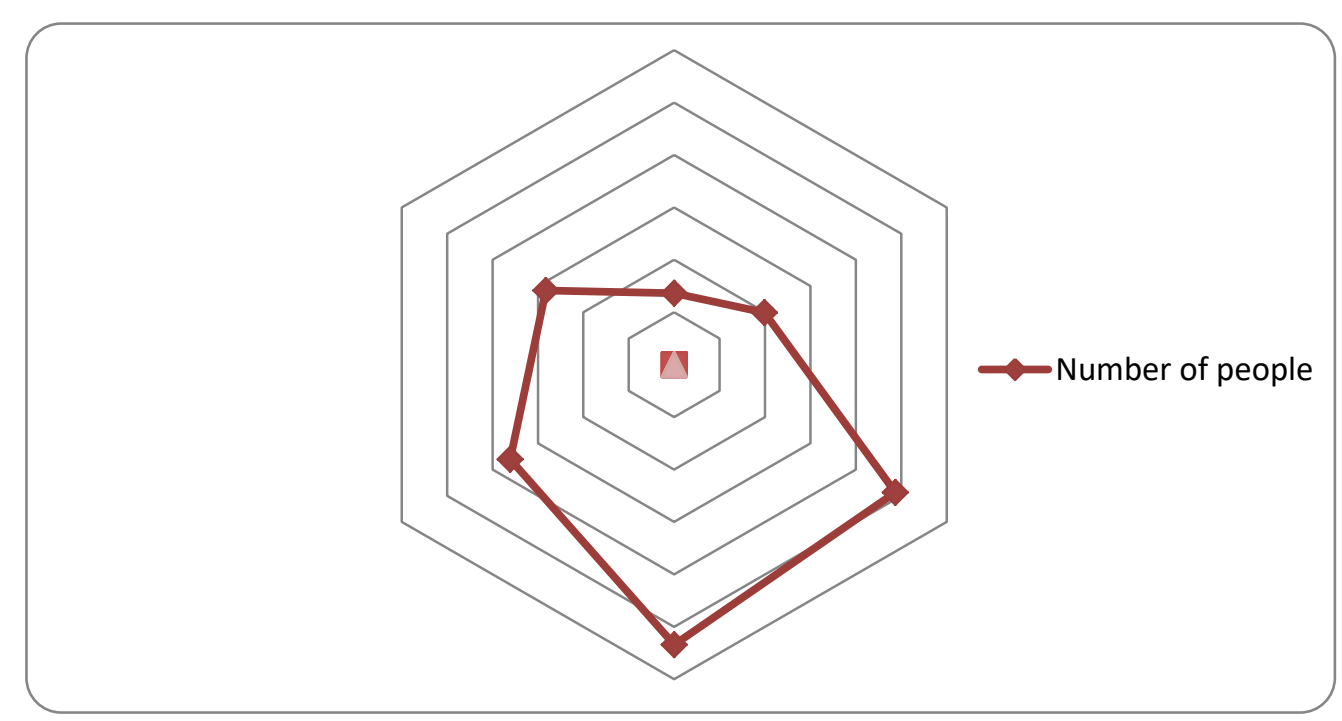

Figure 2. The times that the respondents settled in Bangkok

It can be seen from the above information that there are more women than men in the group of new Chinese migration in Bangkok, the ratio of male to female is $0.76: 1$; in terms of age distribution, most of them are young people $^{1}$, accounting for $73.04 \%$; in the academic qualifications, they are mainly based on undergraduate degree, accounting for $58.38 \%$; the proportion of master's degree is also relatively high, accounting for $25.39 \%$; about the times that the respondents settled in Bangkok, the number of people who settled in Bangkok for 4 to 7 years was relatively large, accounting for $51.05 \%$. 


\section{Identity of New Chinese Immigrants in Bangkok: Statistics and Analysis}

\subsection{Ethnic Identity of New Chinese Immigrants in Bangkok}

The ethnic group of this paper refers to: a specific group of residents living within the sovereignty of a certain country; they generally have their own names and shared memories; they have strong collective identity; they often different with other groups in blood ties, cultural traditions, customs, and physiques; at the same time, ethnic groups do not necessarily have specific territories, and usually do not have political goals (Hao, 2002; Smith, 2006; Zhang, 2017; Yao, 2018; Bao, 2018).

As a new group living in Bangkok, Thailand, the new Chinese immigrants are very consistent in their ethnic identity. Among the 382 valid questionnaires collected, all respondents agreed that they are Chinese. This shows that the ethnic identity with blood and genes as the link is innate and usually will not change with the change of living environment over a relatively long period of time. Shared memories and cultural traditions are integrated into the blood. Whether live in China or live in Bangkok, Thailand, Chinese people always belong to the same ethnic group: ethnic group of Chinese.

\subsection{National Identity of New Chinese Immigrants in Bangkok}

In a sense, there are countries where humans live; that is to say, there has always been a joint organization or autonomous organization that is larger than the family and does not recognize any rights above it (Basanquet, 1996, p. 46; Wang, 2017; Wang \& Ran, 2017; Xue \& Li, 2018). Any ethnic group living in a particular country will involve national identity. The new Chinese immigrants in Bangkok, as an ethnic group living in Thailand, will inevitably involve national identity issues.

4.2.1 Statistical and Analysis of the Overall Situation of National Identity of New Chinese Immigrants in Bangkok

Among the 382 respondents, 173 respondents identify China, accounting for $45.29 \%$; 117 respondents identify Thailand, accounting for $30.63 \%$; and 92 respondents identify both China and Thailand, accounting for $24.08 \%$.
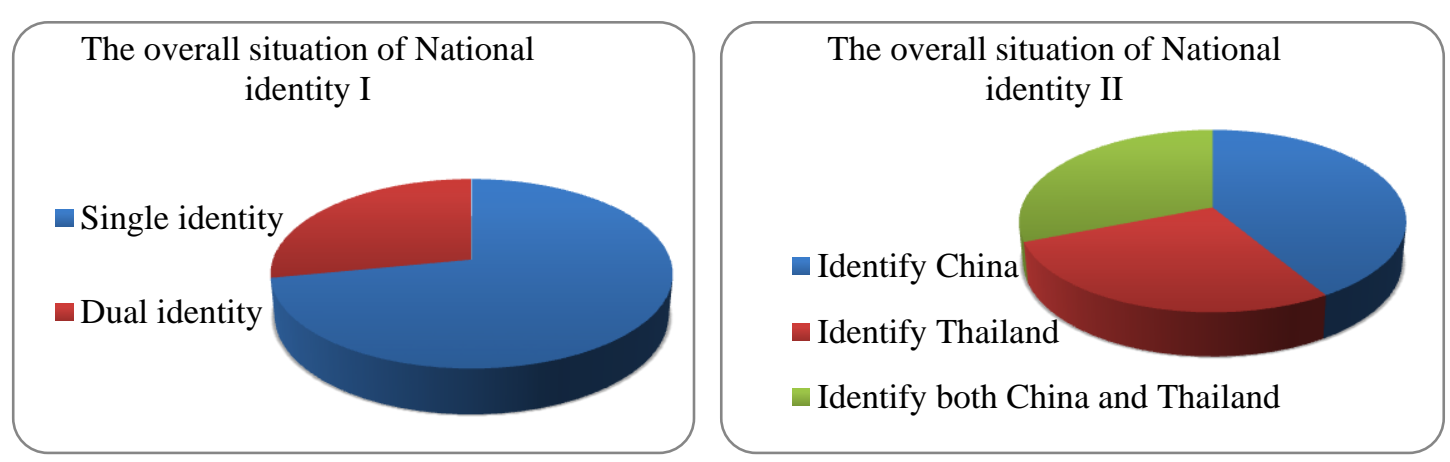

Figure 3. The statistical of the overall situation of national identity of new Chinese immigrants in Bangkok

4.2.2 Statistical and Analysis of the Relationship Between the Times Settled in Bangkok and National Identity of New Chinese Immigrants in Bangkok

The statistical results of the relationship between the times settled in Bangkok and national identity of 382 respondents are as follows: 


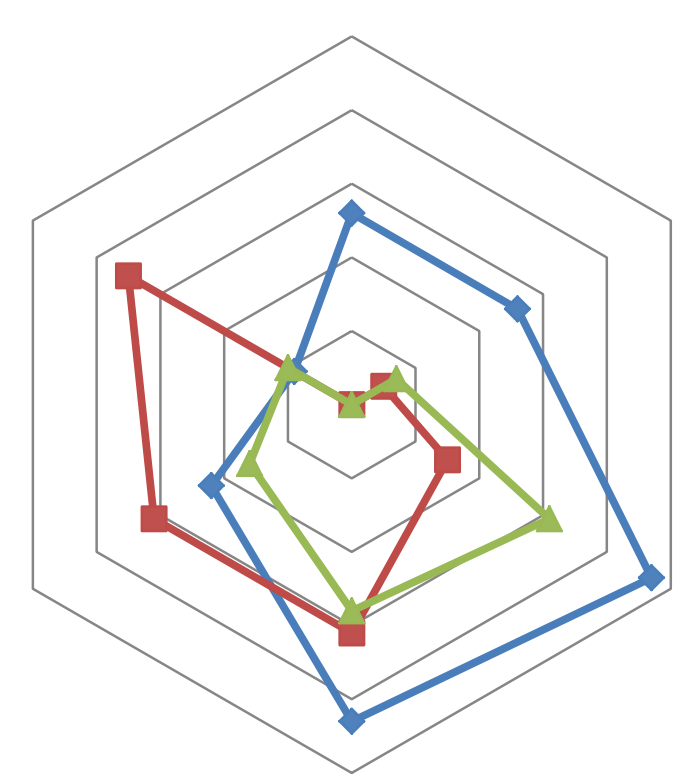

-Identify China 173 - Identify Thailand $117 \_$Identify both China and Thailand 92

Figure 4. Statistical on the relationship between the times settled in Bangkok and national identity of new Chinese immigrants in Bangkok

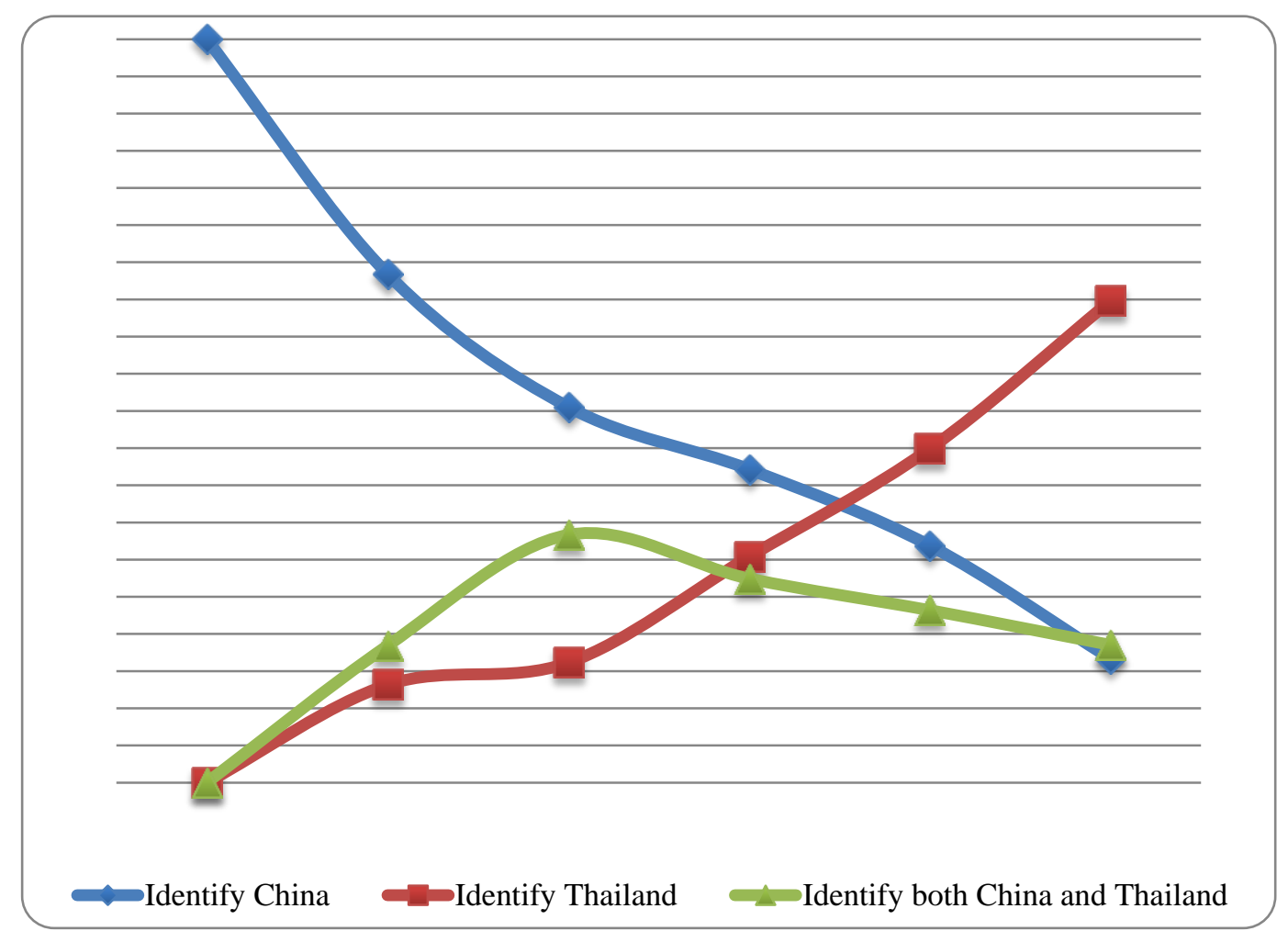

Figure 5. Statistical on the relationship between the times settled in Bangkok and national identity trends of new Chinese immigrants in Bangkok

According to statistics, we can know that:

The degree of identifying China of new Chinese immigrants in Bangkok has declined with the increase of their 
settlement years in Bangkok; however, their degree of identifying Thailand has increased with the increase of settlement years in Bangkok.

The number of people with dual national identity, at the beginning, it has shown an upward trend with the increase of years, reaching a peak in the period of 4 to 5 years, and then showing a downward trend.

In addition, among the new Chinese immigrants in Bangkok, the proportion of the number of people who identify both China and Thailand and who identify Thailand shows the following correlation: Among the number of people who have settled for less than six years in Bangkok, the two is positively correlated; while, among the number of people who have settled for more than six years in Bangkok, the two is negatively correlated.

The above data shows that on the national identity, people of the same ethnic group may have changes on national identity due to the changes of their living areas and social environment.

Ethnic groups always belong to a certain country, and a certain country generally includes multiple ethnic groups (Qian, 2006; Yin, 2018). As long-term living in Bangkok, Thailand, new Chinese immigrants also need to have their own national identity. From the survey data, the national identity of new Chinese immigrants in Bangkok is still in a period of change, and national identity exists diversity.

\subsection{Cultural Identity of New Chinese Immigrants in Bangkok}

"Culture" in ancient China refers to the rule of the emperor and the cultivation of the emperor, which is opposite to "military power" (Zhang \& Ding, 2004, p. 18). Culture in the modern sense refers to the total ability of each ethnic group to adapt to a specific environment and its adaptation results (Zhang \& Ding, 2004, p. 19; Zhang, 2007, p. 23). Any kind of culture is created by a specific ethnic group in a specific environment, reflecting the specificity of human behavior; it also reflects the mutual coordination and coordinated development of people and environment, as well as harmonious coexistence. As people live in different areas, the culture they created and experienced will change, so there will be having some changes in their cultural identity.

4.3.1 Statistical and Analysis of the Overall Situation of Cultural Identity of New Chinese Immigrants in Bangkok

The survey of cultural identity of new Chinese immigrants in Bangkok in this study is divided into three parts: one is the identity of traditional culture, the second is the identity of modern urban culture, and the third is the identity of faith culture. The statistical results of 382 respondents are as follows:

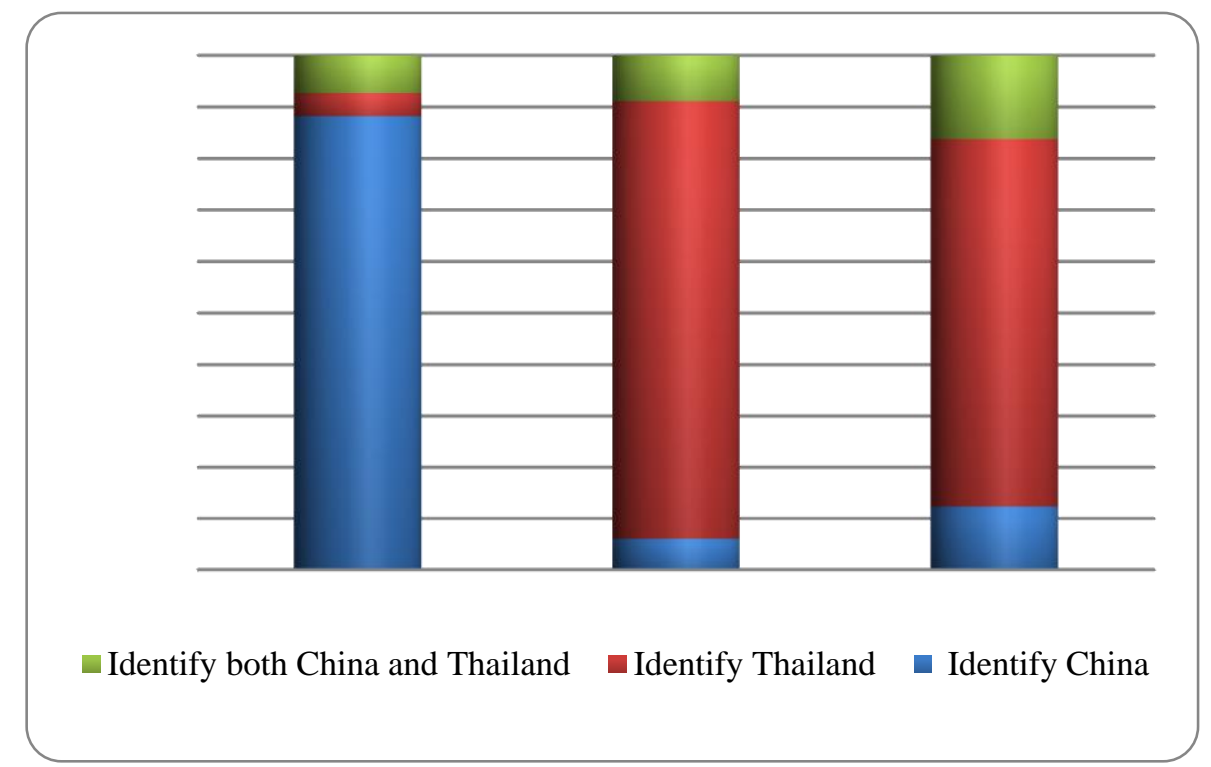

Figure 6. The statistical of the overall situation of cultural identity of new Chinese immigrants in Bangkok

According to statistics, we find that there is diversity in cultural identity among new Chinese immigrants in Bangkok.

First of all, in the traditional cultural identity of new Chinese immigrants in Bangkok, among the 382 respondents, the number of people who identify Chinese traditional culture is 314 , the number of people who identify Thai traditional culture is 25 , and the number of people who identify the traditional culture of both 
China and Thailand is 43. From this data, it can be seen that the new Chinese immigrants in Bangkok are more likely to identify the Chinese traditional culture which is the culture they learned and experienced from childhood.

Secondly, in the modern urban cultural identity of new Chinese immigrants in Bangkok, among the 382 respondents, the number of people who identify Thai modern urban culture is 164, the number of people who identify Chinese modern urban culture is 71 , and the number of people who identify the modern urban culture of both China and Thailand is 147. From this data, it can be seen that the new Chinese immigrants in Bangkok are more likely to identity the modern urban culture of Thailand than identity the modern urban culture of China. The new Chinese immigrants live in Bangkok for a long time, experiencing the modern urban culture of Thailand in their daily life, and these modern urban cultural factors of Thailand have been fully integrated into their daily life.

Thirdly, in the faith culture identity of new Chinese immigrants in Bangkok, among the 382 respondents, the number of people who identify Chinese faith culture is 48 , the number of people who identify Thai faith culture is 273 , and the number of people who identify the faith culture of both China and Thailand is 62. From this data, it can be seen that the new Chinese immigrants in Bangkok are more likely to identify the Thai faith culture, especially the faith culture of Buddhist in Thailand. They will go to the temple to burn incense and worship Buddha as much as the Thai people, praying for peace and wealth. However, some new Chinese immigrants still insist on atheistic beliefs and never burn incense and worship Buddha.

It can be seen from the above survey data that people's cultural identity is closely related to the living environment. The reason why most new Chinese immigrants identity with Chinese traditional culture is because they were born in China and have learned and experienced Chinese traditional culture from a young age. However, as their living environment have changed from China to Bangkok, Thailand, the daily life environment and culture environment of these new Chinese immigrants in Bangkok have changed. Therefore, most new Chinese immigrants have already identity the modern urban culture and faith culture of Thailand.

4.3.2 Statistical and Analysis of the Relationship Between the Times Settled in Bangkok and Cultural Identity of New Chinese Immigrants in Bangkok

The statistical results of the relationship between the times settled in Bangkok and cultural identity of 382 respondents are as follows:

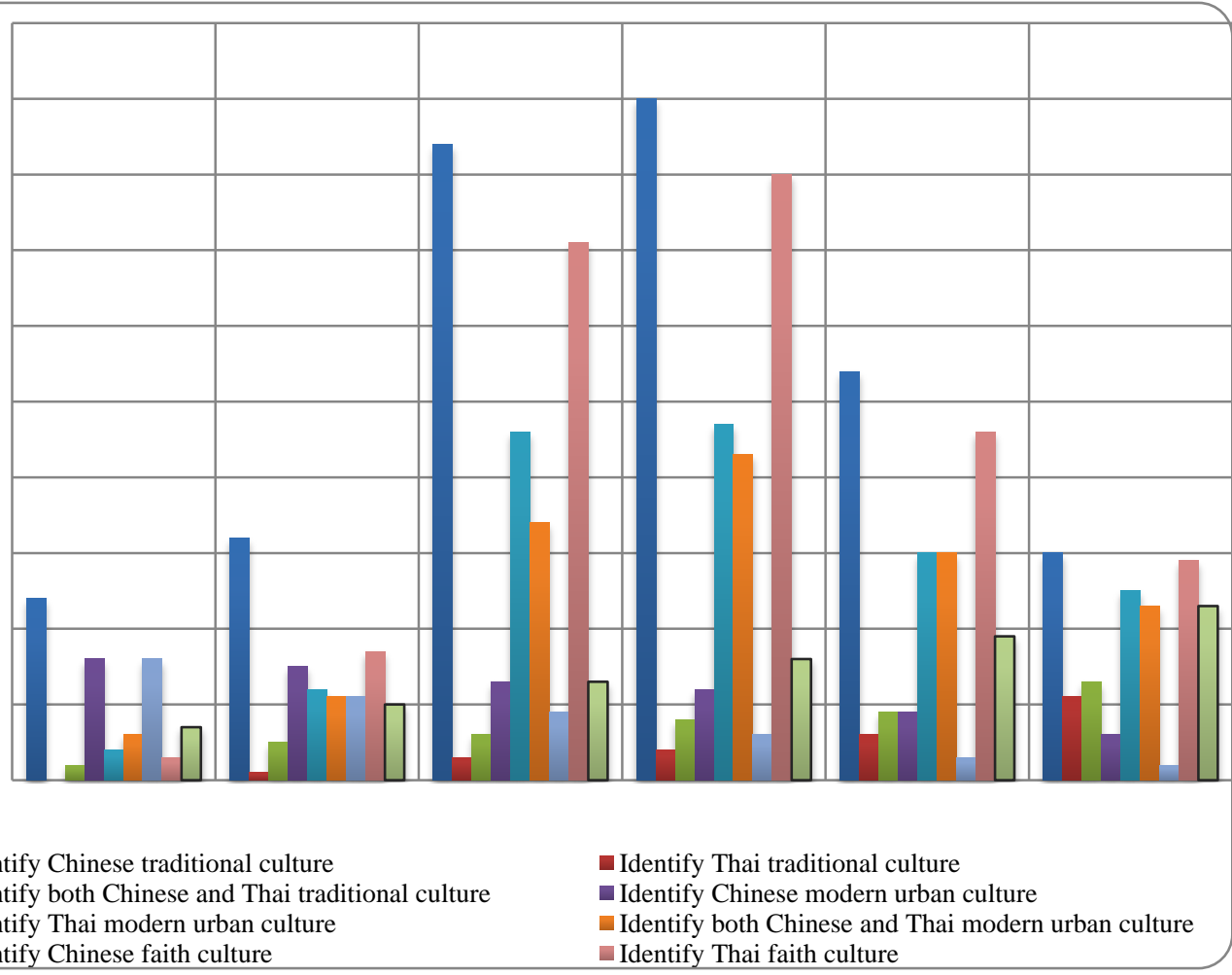

Figure 7. Statistical on the relationship between the times settled in Bangkok and cultural identity of new Chinese immigrants in Bangkok 


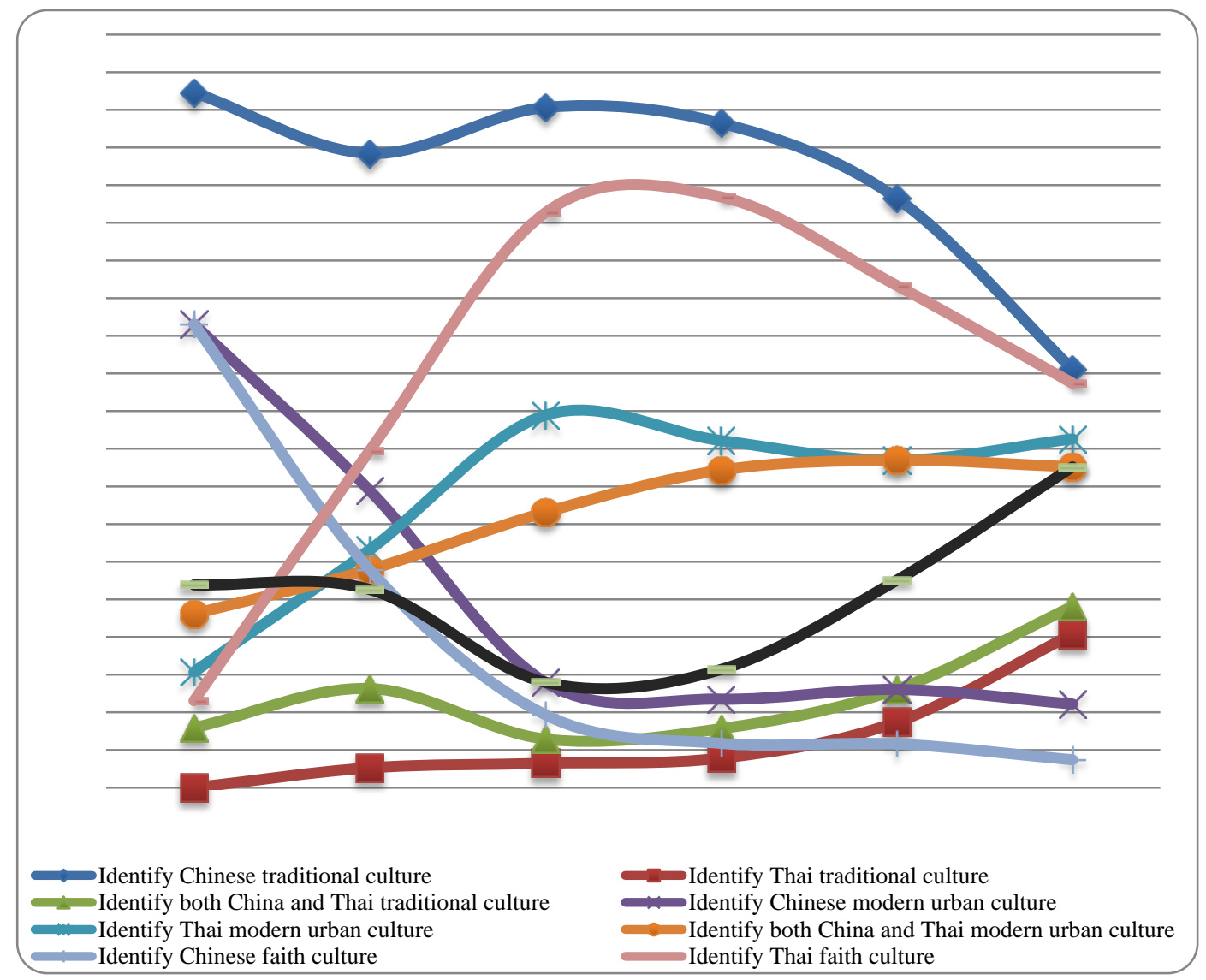

Figure 8. Statistical on the relationship between the times settled in Bangkok and cultural identity trends of new Chinese immigrants in Bangkok

From the above statistics, it can be seen that: 1. The degree of identifying Chinese culture of new Chinese immigrants in Bangkok has declined with the increase of their settlement years in Bangkok; however, their degree of identifying Thai culture has increased with the increase of settlement years in Bangkok; 2. In term of modern urban culture identity, with the increase of their settlement years in Bangkok, the new Chinese immigrants' identity degree of modern urban culture to China and Thailand is positively correlated; 3 . In terms of traditional culture and faith cultural identity, with the increase of their settlement years in Bangkok, the new Chinese immigrants' identity degree of traditional culture and faith cultural to China and Thailand is does not fully negatively correlated.

Culture is a very complex entity. In general, the new Chinese immigrants in Bangkok is increasingly accepting and identifying Thai culture with the increase of their settlement years in Bangkok; however, they did not deny or abandon Chinese culture, lots of people still identify Chinese culture. Especially in the identity of traditional culture, in general, the degree of identifying Chinese traditional culture of new Chinese immigrants in Bangkok has declined with the increase of their settlement years in Bangkok; however, the proportion of people who identify Chinese traditional culture is still much higher than people who identify Thai traditional culture.

\section{Conclusion and Discussion}

This study mainly studies the identity of new Chinese immigrants in Bangkok through questionnaire survey. The study mainly investigates from the following three aspects: ethnic identity, national identity, and cultural identity. Survey results have showed that: The Chinese new immigrants in Bangkok have a consistency on ethnic identity, they all agree that they are Chinese. However, on the national identity and cultural identity, the identity of Chinese new immigrants has multi-tendency.

The identity of any group to their own identity is the result of a combination of internal and external factors. The identity of new Chinese immigrants in Bangkok involves political, economic and cultural factors as well as personal experiences and preferences. About politics, many new Chinese immigrants in Bangkok (accounting for $28 \%$ of respondents) said that they like the liberal democratic atmosphere of Thailand and therefore preferred to identify Thailand in terms of national identity. Others identify China because of the impact of China's economic 
development. Many new Chinese immigrants in Bangkok (43\% of respondents) said that China is currently the third largest economy in the world. The status of such an economic power makes Chinese people oversea more proud, so they are more inclined to identify China.

In addition, in the survey, we found that respondents (about 39\%) engaged in education and culture-related work more identify Chinese culture in cultural identity. They believe that Chinese culture is profound, and is very helpful to their work and life.

In summary, the factors affecting the identity of new Chinese immigrants in Bangkok include: political factors, economic factors, cultural factors, personal experiences and preferences; and each factor plays a different role in various types of identity.

\section{References}

Basanquet, B. (2010). The philosophical theory of the state. Beijing: Commercial Press.

Bao, G. S. (2018). A new reality of western politics: Ethnic-religious pluralism as a challenge to western liberal democracies. CASS Journal of Political Science, 140(3), 105-117, 130. https://doi.org/10.2018-03-011

Hao, S. Y. (2002). An analysis of the interpretation of ethnic groups in western academic circles. Journal of Guangxi University for Nationalities, 4, 14-21. https://doi.org/0.3969/j.issn.1673-8179.2002.04.008

Qian, X. M. (2006). Relationship between ethnic identity and state identity: A perspective from the fundational $\begin{array}{lllll}\text { characteristics of } \quad \text { identity. } & \text { Ethno-National }\end{array}$ https://doi.org/10.3969/j.issn.0256-1891.2006.06.002

Smith, A. D. (2006). Nationalism: Theory, Ideology, History. Shanghai: Shanghai Century Publishing Group.

Wang, G. H., \& Ran, X. D. (2017). Nation-State and national nation: The cognitive basis and interpretation of national traditional sports. Journal of Chengdu Sport University, 43(4), 72-80. https://doi.org/10.15942/j.jcsu.2017.04.011

Wang, J. (2017). Discussion on the concept of national image under the perspective of international political linguistics. Northeast Asian Foreign Language Research, 5(2), 2-9. https://doi.org/10.3969/j.issn.2095-4948.2017.02.002

Xue, Y. F., \& Li, C. C. (2018). The debate between ethnic identity and national identity: The types of relationship between the two and the solution to their dilemma. Guangxi Ethnic Studies, 18(1), 1-9. https://doi.org/10.3969/j.issn.1004-454X.2018.01.001

Yao, S. J. (2018). Ethnic rights in "global cities". Guizhou Ethnic Studies, 206(4), 6-10. https://doi.org/10.13965/j.cnki.gzmzyj10026959.2018.04.001

Yin, J. D. (2018). Environment, ethnic group and territorial space: Regional history view and interpretation path of southwest frontier history research. Journal of Southwest University for Nationalities (Humanities and Social Sciences Edition), 325(9), 219-226. https://doi.org/10.2018-09-032

Zhang G. J., \& Ding, S. Q. (2004). Cultural Linguistics. Beijing: Educational Science Press.

Zhang G. J. (2007). An introduction to Cultural linguistics. Kunming: Yunnan University Press.

Zhang, K. (2017). A review of the relationship between the discrete Chinese oversea and China. Research on the History of Overseas Chinese, 17(2), 10-18. https://doi.org/10.3969/j.issn.1002-5162.2017.02.003

\section{Note}

Note 1. In this paper, the division of ages refers to the new age classification criteria proposed by the United Nations in 2012, young people: under 44 years old, middle-aged people: $45-59$ years old, and older people: over 60 years old.

\section{Copyrights}

Copyright for this article is retained by the author(s), with first publication rights granted to the journal.

This is an open-access article distributed under the terms and conditions of the Creative Commons Attribution license (http://creativecommons.org/licenses/by/4.0/). 